\title{
CONF-\$50476-8
}

UCRL-JC-119378

PREPRINT

\section{Physics Issues Related to the Confinement of ICF Experiments in the U.S. National Ignition Facility}

M. Tobin

A. Anderson

J. Latkowski

M. Singh

C. Marshall

T. Bernat

This paper was prepared for submittal to the 12th International Conference on Laser Interaction and Related Plasma Phenomena

Osaka, Japan

April 24-28, 1995

April 1995

This is a preprint of a paper intended for publication in a journalor proceedinga. Since changes may be made before publication, this preprint is made available with the understanding that it will not be cited or reproduced without the permission of the auther. 


\section{DISCLAIMER}

This document was prepared as an account of work sponsored by an agency of the United States Government. Neither the United States Government nor the University of California nor any of their employees, makes any warranty, express or implied, or assumes any legal liability or responsibility for the accuracy, completeness, or usefulness of any information, apparatus, product, or process disclosed, or represents that its use would not infringe privately owned rights. Reference herein to any specific commercial product, process, or service by trade name, trademark, manufacturer, or otherwise, does not necessarily constitute or imply its endorsement, recommendation, or favoring by the United States Government or the University of California. The views and opinions of authors expressed herein do not necessarily state or reflect those of the United States Government or the University of California, and shall not be used for advertising or product endorsement purposes. 


\section{DISCLAIMER}

Portions of this document may be illegible in electronic image products. Images are produced from the best available original document. 


\title{
Physics Issues Related to the Confinement of ICF Experiments in the U.S. National Ignition Facility*
}

\author{
M. Tobin, A. Anderson, J. Latkowski, M. Singh, \\ C. Marshall, and T. Bernat
}

Lawrence Livermore National Laboratory, P.O. Box 5508, L-481, Livermore, CA 94550

\begin{abstract}
ICF experiments planned for the proposed US National Ignition Facility [NIF] will produce emissions of neutrons, $x$ rays, debris, and shrapnel. The NIF Target Area [TA] must acceptably confine these emissions and respond to their effects to allow an efficient rate of experiments, from 600 to possibly 1500 per year, and minimal down time for maintenance. Detailed computer code predictions of emissions are necessary to study their effects and impacts on Target Area operations. Preliminary results show that the rate of debris shield transmission loss [and subsequent periodicity of change-out] due to ablated material deposition is acceptable, neutron effects on optics are manageable, and preliminary safety analyses show a facility rating of low hazard, non-nuclear. Therefore, NIF Target Area design features such as fused silica debris shields, refractory first wall coating, and concrete shielding are effective solutions to confinement of ICF experiment emissions.
\end{abstract}

\section{Introduction}

The repeated confinement of ICF experiments producing yields up to $20 \mathrm{MJ}$ in the proposed US National Ignition Facility introduces unique challenges. The per shot increase in laser energy between NIF and the existing Nova laser facility, for example, is a factor of 40 , while the increase in total yield will be $10^{5}$. Two of the unique challenges are understanding the characteristics of target emissions (neutrons, $x$ rays, debris, and shrapnel) and their effects on materials; and designing a facility that will meet both stringent environmental standards and an acceptable experiment rate, both for reasonable capital and operational costs.

Here we summarize the results of primarily radiation-hydrodynamics code calculations that predicted NIF target emissions of $x$ rays, debris, and shrapnel as a function of fusion yield, including considerations of two-dimensional effects such as debris jetting and Lambertian x-ray emission. Predicted responses of first wall materials (a refractory material such as plasma-sprayed boron), the debris shield, and the tip of the target positioner is presented, including characteristics of 
the heated material (vapor, melt, spall, etc.), as well as the consequences to NIF operations.

We also discuss the work-in-progress in experimentally assessing the degradation in optical transmission of fused silica and KDP due to neutron and $\gamma$-ray deposition. The specific impacts of pulsed neutron and $\gamma$-ray irradiation and spectral dependence is discussed.

NIF has received a preliminary safety rating as non-nuclear, low hazard. Public dose and occupational exposure are restricted through shielding and the use of low activation material (aluminum). From an environment and safety perspective, the facility site can accommodate individual yields $\leq 45 \mathrm{MJ}$ and an annual total yield of $\geq 2000 \mathrm{MJ}$, enough to encompass the expected demand for access to NIF.

\section{NIF Target Area Design Overview}

Prior to a shot, the target area must provide target chamber vacuum, and a stable platform for the target and its diagnostics. During a shot, the impact of the energy introduced into the chamber must be mitigated, and workers and the public protected from prompt radiation. Careful material selection controls residual radioactivity to allow required accessibility. Tritium and other radioactive wastes are collected and disposed. Diagnostic data is also retrieved, and the facility is readied for the next shot.

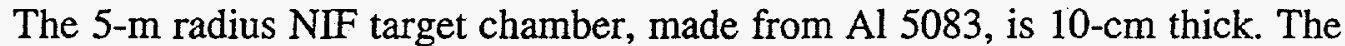
target positioner inserts targets at the chamber 'waist' and laser beam ports are positioned in two concentric cones $\left(27^{\circ}\right.$ and $53^{\circ}$, top and bottom). The final optic, a fused silica debris shield, is $6.75 \mathrm{~m}$ from chamber center. [see Fig. 1](1)

The NIF chamber and target area support structures become radioactive following shots producing neutrons. Shielding on the chamber exterior $[\sim 40 \mathrm{~cm}$ of borated concrete] reduces activation of structures as well as reduces the dose from the radioactive decay of the chamber. Controlled/monitored access to the chamber area is required for hours to several days after shots producing neutrons, depending on the yield. The target chamber support structure is made from aluminum-reinforced, borated concrete to provide stability and minimal radiation levels with reasonable cost. NIF's design lifetime is 30 years. A possible annual shot 'mix' is shown in Table 1. Designing to this shot envelope will ensure adequate facility flexibility.

Table 1. Assumed annual NIF target experiments for design purposes

\begin{tabular}{|c|c|c|}
\hline $\begin{array}{c}\text { Laser Energy } \\
(\mathbf{M J})\end{array}$ & $\begin{array}{c}\text { Number } \\
\text { of shots }\end{array}$ & Target Yield (MJ) \\
\hline \hline 1.0 & $225-600$ & 0 \\
1.5 & $225-600$ & 0 \\
1.8 & $150-300$ & $0.1-20 \mathrm{MJ}$ \\
& $100-250$ & $0.1 \mathrm{MJ}$ \\
& $10-50$ & $20 \mathrm{MJ}$ \\
\hline
\end{tabular}




\section{ICF Target Emissions and Their Effects}

To repeatedly confine NIF fusion experiments, the pressure pulse from the target must be well contained, debris shields must remain at $\geq 97 \%$ transmission by avoiding surface contamination, and neutron activation must be maintained at acceptable levels. A quantitative treatment of the threat to the debris shields requires an understanding of target emissions and materials responses.

\section{$X$ rays}

$\mathrm{X}$-ray and debris emissions were calculated for seven fusion NIF target yields [0.45 to $30 \mathrm{MJ}$ ] with a $1.8-\mathrm{MJ}$ laser drive using the code LASNEX in onedimension (2). The target was modeled as shown in Figure 2 but without the cryogenic support system (e.g. hohlraum only). A 'leak source' was used to model the laser entrance hole, revealing some two-dimensional features to the emission, such as the relative fraction of $x$-ray energy emitted from the hot hohlraum wall as opposed to the laser entrance hole. A Lambertian (cosine) distribution of radiation from the laser entrance holes is assumed. The results are listed in Table 2.

\section{Debris}

Debris is shown in Table 3. The effects of debris jetting have been observed on Nova. We postulate debris jetting with a $37^{\circ}$ half angle, as this is consistent with other two-dimensional calculations done to examine this issue.(3) The mass involved in the jet is inferred from the mass of inward and outward moving material from the LASNEX calculation. The pulse length is determined by the range in material velocity for a given case.

\section{Shrapnel}

Shrapnel generation calculations show that more than five million few-micron average size droplets reach velocities of $\sim 1 \mathrm{~km} / \mathrm{s}$ for a $20-\mathrm{MJ}$ yield.

$$
X \text {-ray Effects }
$$

The target positioner will be protected with a frost-coated plate, where the frost [likely water] will condense from the $\leq 10^{-6}$ Torr chamber vacuum by a cryogenically-cooled panel. Despite several hundred microns of frost removal, no deposition on the debris shield from the positioner is expected since only a noncondensable gas is produced. The first wall surface, likely a boron-based plasma spray material, will be exposed to the $x$-ray and debris fluences listed in Tables 2 and 3 . For a $20-\mathrm{MJ}$ shot, we estimate $120 \mathrm{~g}$ of thermal spray coating to be removed, possibly depositing $\leq 0.2 \mu \mathrm{m}$ on debris shields. This is done by calculating an energy deposition profile in the material due to the absorption of the $\mathrm{X}$-ray fluences and spectra shown in Table 2 . Photon interaction cross sections 
Table 2. X-ray fluences and other characteristics of NIF X-ray target emissions.

\begin{tabular}{|c|c|c|c|c|c|c|c|}
\hline $\begin{array}{c}\text { Shot } \\
\text { Energy \& } \\
\text { Fusion } \\
\text { Yield (MJ) }\end{array}$ & $\begin{array}{c}\text { X-ray } \\
\text { energy } \\
(\mathrm{MJ})\end{array}$ & $\begin{array}{c}\sim B B \\
\text { Temp }(e V)\end{array}$ & $\begin{array}{l}\text { Pulse } \\
\text { (ns) }\end{array}$ & $\begin{array}{c}\text { Target } \\
\text { Positioner } \\
\text { Fluence } \\
\left(\mathrm{J} / \mathrm{cr}_{1}{ }^{2} \text { ) }\right.\end{array}$ & $\begin{array}{c}\text { Peak } \\
\text { 1st Wall } \\
\text { Fluence } \\
\left(\mathrm{J} / \mathrm{cm}^{2}\right)\end{array}$ & $\begin{array}{c}\text { Peak } \\
\text { Debris } \\
\text { Shield } \\
\text { Fluence } \\
\left(\mathrm{J} / \mathrm{cm}^{2}\right)\end{array}$ & \#/year \\
\hline$\leq 1.5$ & $\leq 0.59$ & $60 \% \leq 260$ & $\leq 10$ & 0 & $\leq 0.22$ & $\leq 0.12$ & $\begin{array}{l}450- \\
1200\end{array}$ \\
\hline & & $40 \% \leq 34$ & $\leq 61$ & $\leq 190$ & $\leq 0.08$ & $\leq 0.04$ & \\
\hline Total & & & & $\leq 190$ & $\leq 0.30$ & $\leq 0.16$ & \\
\hline 1.8 & 0.68 & $\begin{array}{c}60 \% @ \\
260\end{array}$ & $\overline{9.9}$ & $\overline{0}$ & 0.26 & 0.13 & $150-300$ \\
\hline & & $40 \% @ 34$ & 61 & 217 & 0.09 & 0.05 & \\
\hline Total & & & & 217 & 0.35 & 0.18 & \\
\hline $100 \mathrm{~kJ}$ & 0.70 & $\begin{array}{c}60 \% @ 8 \\
260\end{array}$ & 9.8 & 0 & 0.27 & 0.13 & $100-250$ \\
\hline & & $40 \% @ 34$ & 62 & 223 & 0.09 & 0.05 & \\
\hline Total & & & & 223 & 0.36 & 0.18 & \\
\hline $20 \mathrm{MJ}$ & 4.23 & $\begin{array}{c}40 \% \text { @ } \\
400 \\
\end{array}$ & 6.3 & 0 & 1.07 & 0.52 & $10-50$ \\
\hline & & $\begin{array}{c}14 \% @ 10 \\
150\end{array}$ & 49 & 469 & 0.19 & 0.10 & \\
\hline & & $46 \%$ @ 47 & 49 & 1558 & 0.62 & 0.34 & \\
\hline Total & & & & 2028 & 1.88 & 0.97 & \\
\hline
\end{tabular}

are taken from the LLNL Evaluated Photon Data Library.(4) For conservatism, we assume all material at or above the incipient melt energy density is removed. The target assembly will deposit $\sim 0.5 \AA$ of material on the debris shield each shot. Total deposition in one week before a $20-\mathrm{MJ}$ shot is a few $\AA$. Therefore, weekly changeout of each debris shield is planned.

\section{Debris Effects}

Although the debris loading is a large total energy fluence, the power is low enough due to long deposition times that thermal conduction effects result in no material being ablated.

\section{Shrapnel Effects}

For a single $20-\mathrm{MJ}$ shot, approximately $3 \%$ of the area of the inside of the chamber in a band near the centerline is pitted.(3) Although shrapnel will ultimately degrade the NIF debris shields due to pitting, we expect ablated material deposition to be the most stressing area. When debris shields are removed for cleaning, any shrapnel damage can be repaired at that time. 
Table 3. Debris fluences and other characteristics of NIF debris target emissions.

\begin{tabular}{|c|c|c|c|c|c|c|}
\hline $\begin{array}{c}\text { Shot } \\
\text { Energy \& } \\
\text { Fusion } \\
\text { Yield (MJ) }\end{array}$ & $\begin{array}{c}\text { Debris } \\
\text { Energy } \\
(M J)\end{array}$ & $\begin{array}{l}\text { Average } \\
\text { Velocity } \\
(\mathrm{cm} / \mu \mathrm{s})\end{array}$ & $\begin{array}{c}\text { Target } \\
\text { Positioner } \\
\text { Fluence } \\
\text { Mass } \\
\text { Pulse }\end{array}$ & $\begin{array}{c}\text { Peak } \\
\text { 1st Wall } \\
\text { Fluence } \\
\text { Mass } \\
\text { Pulse }\end{array}$ & $\begin{array}{c}\text { Peak } \\
\text { Debris } \\
\text { Shield } \\
\text { Fluence } \\
\text { Mass } \\
\text { Pulse } \\
\end{array}$ & \#year \\
\hline \multirow[t]{3}{*}{$\leq 1.5$} & \multirow[t]{3}{*}{$\leq 0.40$} & \multirow[t]{3}{*}{$\leq 8$} & $188 \mathrm{~J} / \mathrm{cm}^{2}$ & $\begin{array}{c}0.33 \\
\mathrm{~J} / \mathrm{cm}^{2}\end{array}$ & $\begin{array}{c}0.18 \\
\mathrm{~J} / \mathrm{cm}^{2}\end{array}$ & \multirow[t]{3}{*}{$\begin{array}{l}450- \\
1200\end{array}$} \\
\hline & & & $\begin{array}{c}104 \\
\mu \mathrm{g} / \mathrm{cm}^{2}\end{array}$ & $68 \mathrm{ng} / \mathrm{cm}^{2}$ & $38 \mathrm{ng} / \mathrm{cm}^{2}$ & \\
\hline & & & $1.35 \mu \mathrm{s}$ & $67 \mu s$ & $91 \mu s$ & \\
\hline \multirow[t]{3}{*}{1.8} & \multirow[t]{3}{*}{0.44} & \multirow[t]{3}{*}{8} & $207 \mathrm{~J} / \mathrm{cm}^{2}$ & $\begin{array}{c}0.37 \\
\mathrm{~J} / \mathrm{cm}^{2}\end{array}$ & $\begin{array}{c}0.20 \\
\mathrm{~J} / \mathrm{cm}^{2}\end{array}$ & \multirow[t]{3}{*}{$150-300$} \\
\hline & & & $\begin{array}{c}104 \\
\mu \mathrm{g} / \mathrm{cm}^{2}\end{array}$ & $68 \mathrm{ng} / \mathrm{cm}^{2}$ & $38 \mathrm{ng} / \mathrm{cm}^{2}$ & \\
\hline & & & $1.35 \mu \mathrm{s}$ & $67 \mu s$ & $91 \mu \mathrm{s}$ & \\
\hline \multirow[t]{3}{*}{$100 \mathrm{~kJ}$} & \multirow[t]{3}{*}{0.46} & \multirow[t]{3}{*}{8} & $216 \mathrm{~J} / \mathrm{cm}^{2}$ & $\begin{array}{r}0.39 \\
\mathrm{~J} / \mathrm{cm}^{2}\end{array}$ & $\begin{array}{c}0.21 \\
\mathrm{~J} / \mathrm{cm}^{2}\end{array}$ & \multirow[t]{3}{*}{$100-250$} \\
\hline & & & $\begin{array}{c}104 \\
\mu \mathrm{g} / \mathrm{cm}^{2}\end{array}$ & $68 \mathrm{ng} / \mathrm{cm}^{2}$ & $38 \mathrm{ng} / \mathrm{cm}^{2}$ & \\
\hline & & & $1.35 \mu \mathrm{s}$ & $67 \mu \mathrm{s}$ & $91 \mu \mathrm{s}$ & \\
\hline \multirow[t]{3}{*}{$20 \mathrm{MJ}$} & \multirow[t]{3}{*}{1.85} & \multirow[t]{3}{*}{16} & $916 \mathrm{~J} / \mathrm{cm}^{2}$ & $\begin{array}{r}1.46 \\
\mathrm{~J} / \mathrm{cm}^{2}\end{array}$ & $\begin{array}{c}0.80 \\
\mathrm{~J} / \mathrm{cm}^{2}\end{array}$ & \multirow[t]{3}{*}{$10-50$} \\
\hline & & & $93 \mu \mathrm{g} / \mathrm{cm}^{2}$ & $87 \mathrm{ng} / \mathrm{cm}^{2}$ & $48 \mathrm{ng} / \mathrm{cm}^{2}$ & \\
\hline & & & $1 \mu$ & $50 \mu \mathrm{s}$ & 00 & \\
\hline
\end{tabular}

\section{Neutron Effects}

The neutron and $\gamma$-ray dose to the debris shields is calculated to be $\sim 2$ krads due to neutrons and $\sim 1 \mathrm{krad}$ for neutron-induced $\gamma$-rays, for a single 20-MJ NIF yield. Therefore, a total NIF lifetime dose could range from $\sim 2$ to 9 Mrad. Previous exposures on RTNS-II indicated that $\mathrm{SiO}_{2}$ did not experience any significant degradation until approximately $20 \mathrm{Mrad}$ total dose. We also find that -300 krads reduces the transmission of fused silica by $<1 \%$ at $3 \omega$. An experiment to investigate whether the short-pulse NIF fluence might cause more damage than the continuous testing fluences was conducted on the Sandia Pulsed Reactor III. For equal doses of radiation [400 krads $\gamma$-ray $/ 160$ krads neutron], delivered over a period of 30 minutes for some samples and in four $100 \mu$ s pulses over 30 hours for others, the samples exposed to the higher flux actually exhibited less reduction in transmission. Further investigations using the LLNL ${ }^{60} \mathrm{Co}$ source revealed that fused silica with as-manufactured no-oxygen deficiency is very hard to $\gamma$-ray irradiation. Fused silica has a potential advantage over fused quartz due to this 
issue. However, after neutron irradiation, fused silica shows susceptibility to $\gamma$-ray damage. This is due to oxygen displacements, creating oxygen-deficient centers for color center damage to accumulate. The oxygen deficient color center is $246 \mathrm{~nm}$. Fortunately, the $246 \mathrm{~nm}$ line is transmuted to $210 \mathrm{~nm}$ by the subsequent $\gamma$-ray radiation. KDP appesis at least as damage resistant as fused silica, although controlling impurities is now known to be a key issue for making KDP hard to radiation damage. Further investigations will explore the effects of the spectral differences between the SPR-III fission source and NIF where the damage is mainly due to $14 \mathrm{MeV}$ neutron deposition. An important difference between the two spectra is average $\gamma$-ray production cross section. The value for $14-\mathrm{MeV}$ is about $10^{3}$ greater than for a fission spectrum. Predictions of the impact of NIF operations on optical performance can be made when the study is completed.

\section{Environment and Safety}

The NIF project is considering expanding the annual shot envelope from 385 to $2000 \mathrm{MJ}$ per year. Recent environmental analyses indicate that the increased annual yield would result in a site boundary dose only $15 \%$ higher $[0.15$ mrem vs. $0.13 \mathrm{mrem}$ ]. Additionally, increasing the largest single shot yield [for environmental considerations] from 20 to $45 \mathrm{MJ}$ results in a lower accident site boundary dose. This dose is substantially due to activated air emissions. The reduction is due to accounting for the elevated release height and mixing with fresh air, aspects ignored in previous analyses. The result is a reduction in dose to an individual at $30 \mathrm{~m}$, from $2.7 \mathrm{rem}$ to $<0.025 \mathrm{rem}$. The significance is the NIF facility non-nuclear rating is based on the dose at 30 -m staying below 10 rem. These analyses show that instead of being within a factor of $\sim 3$ of a possible nuclear rating, NIF is more than a factor of 100 away.

\section{Acknowledgements}

Work performed under the auspices of the U.S. Department of Energy by the Lawrence Livermore National Laboratory under Contract No. W-7405-ENG-48.

\section{References}

1. National Ignition Facility Conceptual Design Report, LLNL, L-16973-1, UCRL-PROP-117093, May 1994.

2. LASNEX and Atomic Theory, LLNL Laser Program Annual Report, Vol 2, UCRL-50021-80, 1980.

3. Tokheim, R., et al., NIF Target Area Design Support, SRI International, Final Report, December 1994.

4. Cullen, D., et al., Tables and Graphs of Photon-Interaction Cross Sections Derived from the LLNL Evaluated Photon Data Library (EPDL), UCRL50400, Vol.6, Rev.4, PartA, Oct. 31, 1989. 


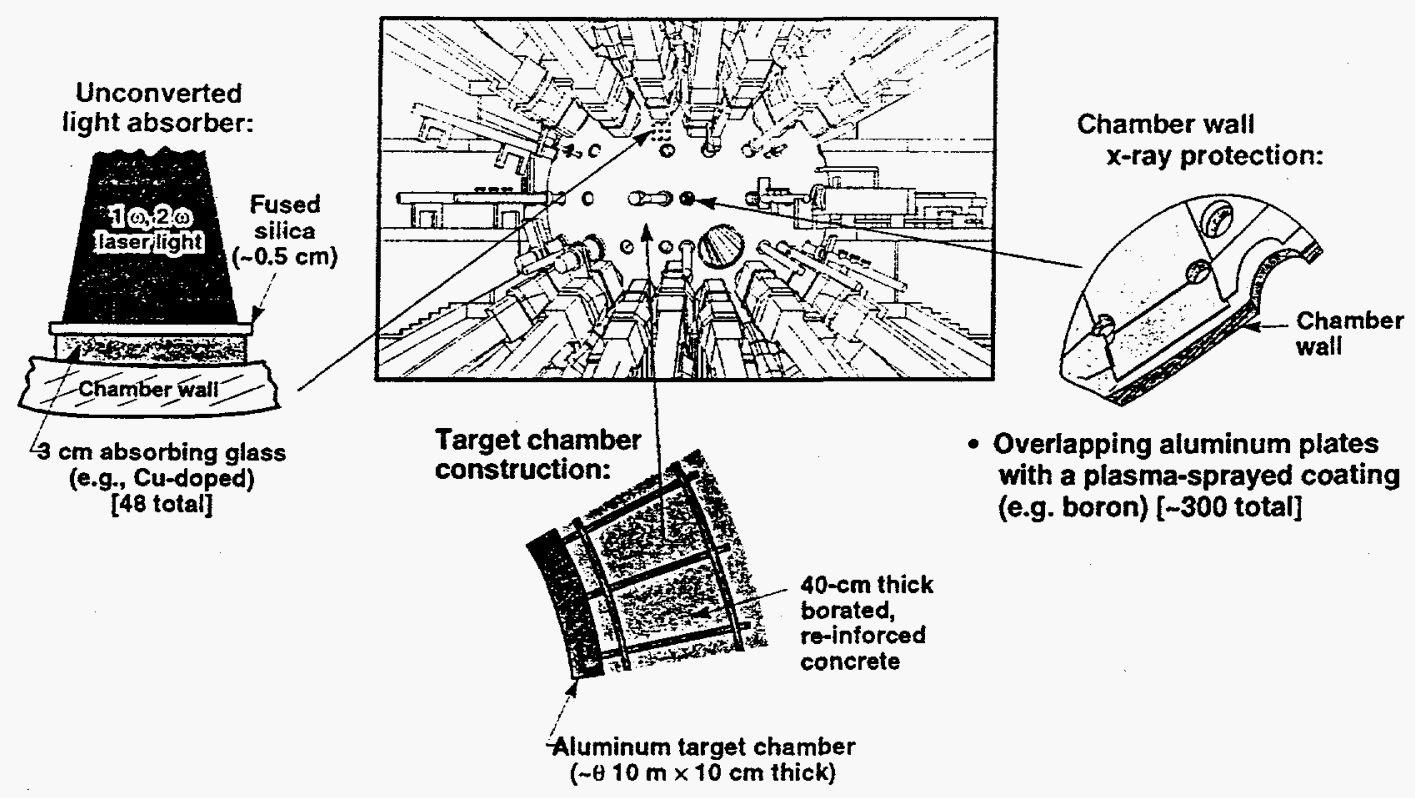

Figure 1. The NIF Target Area chamber will require several specialized components to mitigate the effects of target emissions.

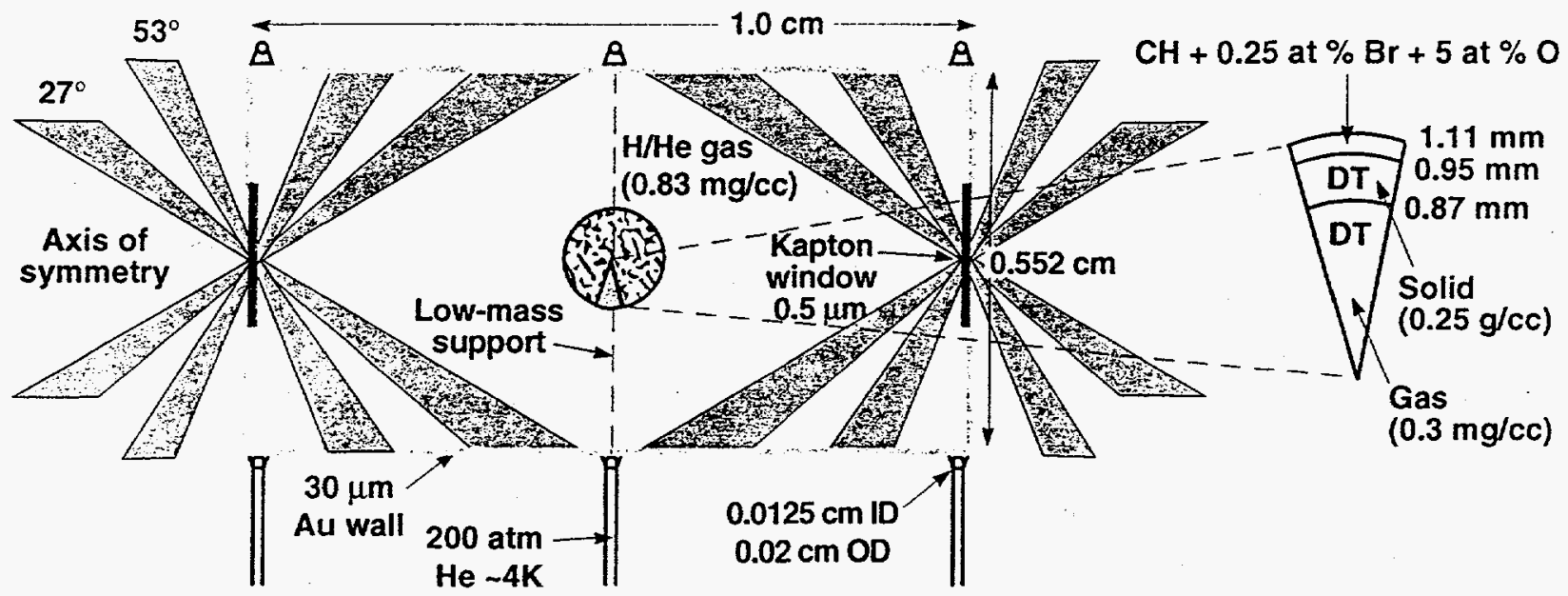

Figure 2. A possible NIF target design that may achieve as much as $20-\mathrm{MJ}$ yield. Target will be inserted from the horizontal on cryogenic capillary tubes.

70-37-0495-1021pb01 